\title{
Sub-threshold depression and antidepressants use in a community sample: searching anxiety and finding bipolar disorder
}

\author{
Mauro G Carta ${ }^{1 *}$, Leonardo Tondo ${ }^{2}$, Matteo Balestrieri ${ }^{3}$, Filippo Caraci ${ }^{4}$, Liliana dell'Osso ${ }^{5}$, Guido Di Sciascio ${ }^{6}$, \\ Carlo Faravelli ${ }^{7}$, Maria Carolina Hardoy ${ }^{1,8}$, Maria E Lecca ${ }^{1}$, Maria Francesca Moro ${ }^{1}$, Krishna M Bhat ${ }^{9}$, \\ Massimo Casacchia ${ }^{10}$ and Filippo Drago ${ }^{4}$
}

\begin{abstract}
Background: To determine the use of antidepressants (ADs) in people with sub-threshold depression (SD); the lifetime prevalence of mania and hypomania in SD and the link between ADs use, bipolarity and anxiety disorders in SD.

Methods: Study design: community survey. Study population: samples randomly drawn, after stratification from the adult population of municipal records. Sample size: 4999 people from seven areas within six Italian regions. Tools: Questionnaire on psychotropic drug consumption, prescription; Structured Clinical Interview NP for DSM-IV modified (ANTAS); Hamilton Depression Rating Scale (HAM-D); Mood Disorder Questionnaire (MDQ); Short Form Health Survey (SF-12). SD definition: HAM-D > 10 without lifetime diagnosis of Depressive Episode (DE).

Results: SD point prevalence is 5.0\%. The lifetime prevalence of mania and hypomania episodes in SD is $7.3 \%$. Benzodiazepines (BDZ) consumption in SD is $24.1 \%$, followed by ADs (19.7\%). In SD, positive for MDQ and comorbidity with Panic Disorder (PD) or Generalized Anxiety Disorders (GAD) are associated with ADs use, whereas the association between a positive MDQ and ADs use, without a diagnosis of PD or GAD, is not significant. Only in people with DE the well-being (SF-12) is higher among those using first-line antidepressants compared to those not using any medication. In people with SD no significant differences were found in terms of SF-12 score according to drug use.
\end{abstract}

Conclusions: This study suggests caution in prescribing ADs to people with SD. In people with concomitant anxiety disorders and SD, it should be mandatory to perform a well-designed assessment and evaluate the presence of previous manic or hypomanic symptoms prior to prescribing ADs.

\section{Background}

Patients with mild-to-moderate, chronic or episodic dysthymia and anxiety may not benefit greatly from antidepressant treatment [1]. According to this study, antidepressants have limited short-term efficacy in unipolar depressive disorders and even less in acute bipolar depression. Moreover their long-term prophylactic effectiveness in recurrent unipolar major depression remains uncertain and is doubtful in bipolar depression [1]. These limitations may, in part, reflect the excessively broad concept of unipolar depression. The current

\footnotetext{
* Correspondence: mgcarta@tiscali.it

'Department of Public Health, University of Cagliari, Cagliari, Italy

Full list of author information is available at the end of the article
}

subtyping of depression is based on the DSM-IV-TR categorical division of bipolar and depressive disorders. Current evidence, however, supports a dimensional approach to depression, as a continuum/spectrum of overlapping disorders, ranging from bipolar I depression to major depressive disorder [2].

Treatment-refractory depression may reflect failure to distinguish depressive conditions, particularly in bipolar disorder, that are inherently less responsive to antidepressants. Antidepressants probably should be avoided in bipolar depression, mixed manic-depressive states, and in neurotic depression. Expectations of beneficial effects of antidepressant treatments for specific types of

\section{() BiolMed Central}

(C) 2011 Carta et al; licensee BioMed Central Ltd. This is an Open Access article distributed under the terms of the Creative Commons Attribution License (http://creativecommons.org/licenses/by/2.0), which permits unrestricted use, distribution, and reproduction in any medium, provided the original work is properly cited. 
patients with symptoms of depression or anxiety require critical re-evaluation.

Taking into account the hypothesis that in sub-threshold depressions (SDs) the use of antidepressants may be ineffective, this study aims to examine this hypothesis in a large community sample:

1) The amount of use of antidepressants in people with depressive symptoms (HAM-D > 10) without lifetime diagnosis of Depressive Episode (DE).

2) The lifetime prevalence of mania and hypomania in such subjects.

3) The role of anxiety disorders in the use of antidepressants in people with SD.

4) The link between antidepressants use, bipolarity and anxiety disorders in SD.

5) Whether or not subjects with SD treated with antidepressants actually need to be treated.

\section{Methods}

Design

The study is a community survey based on the database of the National Italian Survey "The use of antidepressants in Italy" [3]. Face-to-face interviews were carried out at candidates' homes.

\section{Recruitment methods and study sample}

The study sample was randomly drawn from the adult population of municipal records in seven different areas from different Italian locations with wide variations in socio-economic conditions: [a] Sicily (Catania), [b] Sardinia (Iglesias), and [c] Puglia (Bari) in southern Italy; [d] Abruzzo (L'Aquila) and [f] Tuscany (Florence and Pisa) in central Italy; [g] Friuli-Venezia Giulia (Udine) in northern Italy. In each area, both urban and rural subareas were selected. The sample of Florence (Sesto-Fiorentino) was only urban and Pisa was only rural. A third of the sample in each centre was drawn from three variously populated municipalities; less than 2,000 , from 2,001 to 10,000 inhabitants, and from 10,001 to 20,000 inhabitants.

Randomization was performed after stratification by sex and four different age groups (18-24; 25-44; 45-64; > 64).

Using the above mentioned methodology, a sample of 4999 people was drawn from the seven areas. The size of the subsamples were: 704 in L'Aquila; 971 in Bari; 666 in Catania; 846 in Florence; 465 in Iglesias; 464 in Pisa, and 882 in Udine.

Subjects were contacted at home by phone or by mail by the local coordinator of the study.

\section{Interview, tools and study assessment}

Interviews were carried out using the following tools:
1. Ad-hoc form to assess basic demographic data and psychotropic drug consumption, prescription circumstances and health-services utilization previously used and validated in a regional survey [4]. For all the subjects, consumption of antidepressant drugs was ascertained. Positive use was identified as subjects consuming antidepressant drugs at therapeutic dosages for every day for at least 15 days prior to the interview.

2. The "Advanced Neuropsychiatric Tools and Assessment Schedule" (ANTAS), a computerized semi-Structured Clinical Interview derived from the non patient version (SCID-I/NP) for DSM-IV [5] to assess the presence of psychiatric disorders (this, as stated in the study protocol, requires a clinical competence to administer). A reliability study of the diagnosis derived from the ANTAS compared to SCID has been carried out and the results have been previously published [6]. The results for mood and anxiety diagnosis with SCID showed a mean $k$ of $0.85[3,6]$.

3. The Mood Disorder Questionnaire (MDQ) ([7], Italian version [8]) for the assessment of bipolar spectrum disorders.

4. The depressive symptoms were measured by means of Hamilton Depression Rating Scale (HAMD), [9].

5. Quality of life was evaluated with the Short Form Health Survey (SF-12) [10]. The SF-12 includes the following dimensions: physical activity, physical health limitations on role or activities, emotional state, physical pain, self-evaluation of general state of health, vitality, social activity and mental health. The period of measurement is the previous month. Highest scores correspond to better conditions and quality of life.

For the purpose of the present study we used these definitions:

1. $\mathrm{SD}=$ people having, at the time of the interview, depressive symptoms (HAM-D score > 10) without an ANTAS-SCID-DSM-IV lifetime diagnosis of Depressive Episode.

2. Depressive Episode (DE) point prevalence = people with an ANTAS-SCID-DSM-IV Depressive Episode diagnosis at the time of the interview; they may have a lifetime ANTAS diagnosis of Major Depressive Disorder (MDD) or Bipolar Disorder (BD).

3. Not Depressed (ND) people $=$ people not showing any relevant depressive symptoms at the time of the interview (HAM-D score $<10$ ).

4. Lifetime diagnosis of manic-hypomanic episode in SD = people having MDQ lifetime positivity (score $>7$ ). 
All the people interviewed in the community were included in the analysis.

\section{Interviewers and training}

Interviewers were selected from psychologists and physicians with at least two years of experience in clinical psychiatric work following graduation.

They received a common and intensive training in the use of the research instrument and administration of home interviews by the Coordinating Unit.

Interviewers were provided with a laptop computer and software to record data during the interview.

Two assistant researchers from the Coordinating Unit traveled to each field unit and interviewed at least seven patients and three control subjects who had been interviewed by the local interviewers. Differences in results were discussed and resolved. The diagnosis reliability between coordinator researchers and each unit had a $k$ mean higher than 80 .

\section{Monitoring and Quality Control}

Interview quality was monitored by cross-examining the interviewers every three months and having at least 120 interviews repeated by different interviewers.

\section{Sample Size}

It was envisaged that from $60 \%$ to $65 \%$ of the original sample (a planned sample of at least 4,800 interviews) would take part in the survey ( $5 \%$ of members were expected to be deceased or moved, $10 \%$ were expected to be non retrievable and $20 \%$ were considered the refusal rate) for an expected total of about 3,000 interviewed subjects. This sample size was expected to provide a $95 \%$ confidence interval of $\pm 0.036 \%$ of the expected prevalence summary estimate of $4 \%$ of both antidepressant consumption and bipolar disorders as MDQ positives (relative standard error being around 7\%). This sample was also planned for recording SD (main objective of the present study), considering that the expected point prevalence of SD was 6-9\%. This is because, the ECA study of Judd and Coll [11] found a prevalence of $11.8 \%$ using a less inclusive diagnosis. A similar frequency was also found in the Zurich study by Angst and Coll [12].

\section{Ethical Aspects}

An informed consent for the use of anonymous data suitable for an aggregate study was signed by each candidate. The study was approved by the ethical committee of the Italian National Health Institute (Rome). Data were not nominal at source and each subject was identifiable with a code number.

\section{Results}

The characteristics of the enrolled sample by age, sex and the rate of non-interviewed have been already published [3]. No significant statistical differences were found between the interviewed sub-samples and the randomized sub-samples according to age and sex [3].

A total sample of 3389 subjects was enrolled (57.7\% female).

Table 1 shows the prevalence of SD by sex in the total sample. At the time of interview, 5.0\% of the sample had SD. SD is more frequent in females than in men $(5.5 \%$ vs $2.0 \%$, OR $=2.86$ CL95\% 1.4-4.3). The prevalence of lifetime mania and hypomania episodes in people with $\mathrm{SD}$ is $7.3 \%$ (6.5 in females, 10.5 in males). The table shows that the prevalence of mania and hypomania in $\mathrm{SD}$ is lower than in people with DE but higher than in the overall sample without depressive symptomatology (SD or DE) at the time of the interview.

Table 2 shows the psychoactive drugs and other treatments consumed by people with SD in the overall sample and by sex. Benzodiazepines (BDZ) are the drugs with highest consumption (24.1\%) followed by antidepressants (19.7\%). First line antidepressants (including SSRI, TCA, IMAO, SNRI, NaSSA and Bupropion) are used by $14.6 \%$ of the sample and second line antidepressants (low-dosage Benzamides, low-dosage Quetiapine, Trazodone, Nefazodone, Adenosin-methionine and Hypericum Perforatum) by the remaining 5.1\%. We note that low-dosage Benzamides are available for minor depression only in Italy. Psychotherapies are well represented $(9.5 \%)$ and homeopathic treatments are limited (2.9\%). The use of antidepressants and benzodiapines is more frequent among females with SD than among males with SD, but the difference is not statistically significant.

When we compare the use of psychoactive drugs and other treatments in the overall sample, in ND subjects, subjects with DE point prevalence and in subjects with SD (Table 3), the frequencies of use of first-line and second-line antidepressants rank as follows: subjects with $\mathrm{DE}>\mathrm{STD}>\mathrm{ND}$. Treatments with BDZ and psychotherapy do not show any difference between DE and STD, but these two groups show higher use than ND people. Homeopathic treatments seem to be typically used in SD with a statistically significant difference only when compared to ND people.

No demographic factors (sex, age, geographic distribution) appear to be of relevance in the frequency of prescription of antidepressants in the SD sample (Table 4). Of relevance, in people with SD, a positive MDQ diagnosis is associated with antidepressant use (the calculation was carried out after standardizing for sex and age).

Comorbidity with PD or GAD is also associated with the use of antidepressant drugs. Re-calculating the weight of the association between MDQ positivity and antidepressants use, standardizing by having a diagnosis of PD or GAD, the significance of association disappears 
Table 1 Prevalence of Sub-threshold Depression (SD) (HRDS > 10 without criteria for lifetime Depressive Episode) by sex and frequency of Mania and Hypomania detected by MDQ in SD, Depressive Episode point prevalence = DE and in the overall sample without depressive depression (SD or DE) $=N D$, by sex

\begin{tabular}{|c|c|c|c|c|c|c|c|c|c|c|}
\hline & Male & $\%$ & Female & $\%$ & Total & $\%$ & OR (F) & CL 95\% & $\mathrm{X} 21 \mathrm{df}$ & $\mathbf{P}$ \\
\hline$\underline{\text { SD }}$ & 29 & 2.0 & 108 & 5.5 & 137 & 5.0 & 2.86 & $1.4-4.3$ & 25.5 & $<0.0005$ \\
\hline 1. MDQ in SD & 3 & 10.3 & 7 & 6.5 & 10 & 7.3 & 0.6 & $0.24-1.39$ & 0.10 & 0.76 \\
\hline 2. MDQ in DE & 4 & 23.5 & 11 & 28.9 & 15 & 27.3 & 1.3 & $0.41-2.10$ & 0.01 & 0.92 \\
\hline 3. $\mathrm{MDQ}$ in ND & 42 & 3.0 & 36 & 2.0 & 78 & 2.4 & 0.6 & $0.34-1.05$ & 3.14 & 0.08 \\
\hline MDQ in the overall sample & 49 & 3.4 & 54 & 2.7 & 103 & 3.0 & 0.8 & $0.5-1.2$ & 1.00 & 0.312 \\
\hline $\begin{array}{l}\text { X2 by columns } \\
3 \mathrm{df}\end{array}$ & 25.7 & & 107.0 & & 100.4 & & & & & \\
\hline$P$ & 0.0001 & & 0.0001 & & 0.0001 & & & & & \\
\hline
\end{tabular}

Homogeneity by cells in columns (1DF):

Column Male 1vs2, $\chi 2=0.6, \mathrm{P}=0.43 ; 1 \mathrm{vs} 3, \chi 2=2.86, \mathrm{P}=0.09 ; 2 \mathrm{vs} 3 \chi 216.3, \mathrm{P}<0.001 ;$ Column Female1vs2, $\chi 2=11.1, \mathrm{P}<0.001 ; 1 \mathrm{vs} 3, \chi 2=7.05, \mathrm{P}=0.006 ;$ 2 vs3 $\chi 2=98.8, \mathrm{P}<0.0001 ;$ Column Total 1vs2, $\chi 2=12.5, \mathrm{P}<0.001 ; 1 \mathrm{vs} 3, \chi 2=6.4, \mathrm{P}<0.01 ; 2 \mathrm{vs} 3 \chi 2=91.2, \mathrm{P}<0.0001$.

$\left(\chi^{2}=1.6(1 \mathrm{df}), p=0.2\right.$, OR $\left.=2.6\right)$. Thus, the basis for taking antidepressants is the anxiety disorder and MDQ positivity is probably occurring as a confounding factor.

Table 5 analyzes the well being of the subjects in the sample, measured with SF-12, according to the diagnosis and the treatment of $\mathrm{BDZ}$ and antidepressants. In the community, only in people with DE the well-being is higher in those using first-line antidepressants compared to those not using any medication. Moreover, no differences are observed for the second-line antidepressants or BDZ. In people with SD no differences are found even for first-line antidepressant.

\section{Discussion}

The study indicates that around 5\% of people in the community have SD and that SD is higher in women than in men (5.5 vs $2 \%$ ). People with SD have a lifetime prevalence of manic and hypomanic episodes detected by MDQ (7.3\%). This frequency falls in the middle, between people without depression (DE or SD) at the time of interview (2.4\%) and people with $\mathrm{DE}$ (27.3\%). If we consider that SD is more prevalent than $\mathrm{DE}$ in the community ( $5 \%$ vs $2.4 \%$ ), the relevance of MDQ positivity at the community level is quite similar in DE (MDQ positivity $0.4 \%$ of the whole community sample) and in SD (MDQ positivity $0.3 \%$ of the sample). This is an interesting point because it is intuitive that the identification of a previous manic or hypomanic episode should be easiest in people with a clear diagnosis of DE.

For the purpose of this study we decided to compare the lifetime prevalence of MDQ Positivity in people showing symptoms of DE without a lifetime diagnosis of $\mathrm{DE}$ and in people with DE at the time of interview. Our purpose is to define how much is of clinical and public health relevance if a person with depressive symptoms at the time of a hypothetical clinical contact but without prior diagnosis of depressive episode has manic or hypomanic lifetime episode and how much this phenomenon may be related with the antidepressants use. In this sense the definition of SD as people having a HAM-D score of $>10$ is an operational choice for detecting people without diagnosis of DE but with a relevant depressive symptomatology that may result in antidepressant prescription.

We take into account that the diagnosis of Mania and Hypomania by SCID may be too restrictive [13] and we also use the MDQ positivity to measure the "bipolarity spectrum". The under recognition of BD in people with $\mathrm{DE}$ is not the specific objective of this study; this topic has been addressed in another study using the same database [14].

Table 2 Psychoactive drugs and other treatments in Sub-threshold Depression (HRDS > 10 without lifetime criteria for Depressive Episode) by sex

\begin{tabular}{|c|c|c|c|c|c|c|c|c|c|c|}
\hline Treatment & Males & $\%$ & Females D & $\%$ & Total (males and females) & $\%$ & OR (F) & CL 95\% & X2 1df & $P$ \\
\hline First-line Antidepressants ${ }^{\circ}$ & 2 & 6.8 & 18 & 16.6 & 20 & 14.6 & 2.7 & $0.1-96.4$ & 1.05 & 0.30 \\
\hline Second-line Antidepressants§ & 1 & 3.4 & 6 & 5.6 & 7 & 5.1 & 1.6 & $0.1-31.2$ & 0.1 & 0.98 \\
\hline Benzodiazepines* & 7 & 24.1 & 33 & 30.6 & 40 & 24.1 & 1.4 & $0.2-6.3$ & 0.2 & 0.66 \\
\hline Homeopathics & 1 & 3.4 & 3 & 2.7 & 4 & 2.9 & 0.8 & $0.3-2.1$ & 0.2 & 0.68 \\
\hline Psychotherapy & 3 & 10.3 & 10 & 9.2 & 13 & 9.5 & 0.9 & $0.4-2.0$ & 0.1 & 0.86 \\
\hline
\end{tabular}

oSSRI, TCA, IMAO, SNRI, NaSSA, bupriopion; § low-dosage benzamides, low-dosage quetiapine, trazodone, nefazodone, Adenosin-methionine, Hypericum Perforatum 
Table 3 Comparison of psychoactive drugs use and other treatments in Sub-threshold Depression (HRDS > 10 without criteria for lifetime Depressive Episode) = SD; subjects with Depressive Episode point prevalence = DE and in the overall sample without Depression (SD or DE) = ND

\begin{tabular}{lllllll}
\hline & 2. SD & 3. DE & 1. ND & Overall Sample & X2 2DF & P \\
\hline Total & $137(4.0)$ & $55(1.6)$ & $3206(94.3)$ & 3398 & & \\
\hline${ }^{\circ}$ First line Antidepressants & $20(14.6)$ & $17(30.9)$ & $69(2.1)$ & $106(3.1)$ & 210.2 & 0.0001 \\
\hline \$Second line Antidepressants & $7(5.1)$ & $14(25.4)$ & $32(1.0)$ & $53(1.6)$ & 14.7 & 0.0001 \\
\hline *Benzodiazepines & $40(29.1)$ & $14(25.4)$ & $188(5.8)$ & $242(7.1)$ & 147.9 & 0.0001 \\
\hline${ }^{\circ}$ Homeopathics & $4(2.9)$ & 0 & $21(0.6)$ & $25(0.7)$ & 8.1 & 0.018 \\
\hline **Psychotherapies & $13(9.5)$ & $8(17.8)$ & $50(1.5)$ & $71(2.1)$ & 95.3 & 0.0001 \\
\hline
\end{tabular}

${ }^{\circ}$ Homogeneity by cells: $1 \mathrm{vs} 2, \chi 2=74.1,1 \mathrm{DF} \mathrm{P}<0.0001 ; 1 \mathrm{vs} 3, \chi 2=205.7,1 \mathrm{DF} \mathrm{P}<0.0001 ; 2 \mathrm{vs} 3 \chi 2=9.8,1 \mathrm{DF} 0.002 ;$ §Homogeneity by cells: $1 \mathrm{vs} 2, \chi 2=12.5,1 \mathrm{DF}$ $\mathrm{P}<0.0001 ; 1 \mathrm{vs} 3, \chi 2=76.3,1 \mathrm{DF} \mathrm{P}<0.0001 ; 2 \mathrm{vs} 3, \chi 2=14.6, \mathrm{P}<0.0001 ; 2 \mathrm{vs} 3 \chi 2=5.6,1 \mathrm{DF} \mathrm{P}=0.018 ;{ }^{*}$ Homogeneity by cells: $1 \mathrm{vs} 2, \chi 2=109.4,1 \mathrm{DF} \mathrm{P}<0.0001$; 1vs3, $\chi 2=44.5$, 1DF P $<0.0001 ; 2 \mathrm{vs} 3 \chi 2=0.1$, 1DF NS; ${ }^{\circ}$ Homogeneity by cells: $1 \mathrm{vs} 2, \chi 2=4.6,1 \mathrm{DF} \mathrm{P}<0.031 ; 1 \mathrm{vs} 3, \chi 2=0.1,1 \mathrm{DF}$ NS; $2 \mathrm{vs} 3 \chi 2=0.3,1 \mathrm{DF}$ NS; $* *$ Homogeneity by cells: $1 \mathrm{vs} 2, \chi 2=40.4,1 \mathrm{DF} P<0.0001 ; 1 \mathrm{vs} 3, \chi 2=45.0,1 \mathrm{DF} \mathrm{P}<0.0001 ; 2 \mathrm{vs} 3 \chi 2=0.5,1 \mathrm{DF}$ NS

The results of our community study show that people with SD use largely the first- (14.6\%) and the secondline antidepressants (5.1\%), as well as BDZ (24.1\%). The consumption of antidepressants is similar in people with $\mathrm{SD}$ and $\mathrm{DE}$, only smaller for the first-line antidepressants but higher for all other medications than in people without depressive symptoms. The use of antidepressants in SD is more significant with comorbidity factors $\mathrm{PD}$ or GAD as per treatment guidelines, indicating antidepressants as the first-line of treatment for PD $[15,16]$ and GAD [17].

Nevertheless in our community sample, the diagnoses of PD or GAD are strictly associated with MDQ positivity. This is expected given the recent findings in a recent study [18] determining any confounding relationship between MDQ positivity and antidepressant use in people with SD. In fact, antidepressants are frequently used in the sub-sample with a previous manic or hypomanic episode, detected by MDQ, with a high risk for developing $\mathrm{BD}$ (even without a $\mathrm{DE}$ ).

Table 4 Determinants of all ADs (first and second line) prescriptions in Sub-threshold Depression (HRDS > 10 without criteria for lifetime Depressive Episode)

\begin{tabular}{llllll}
\hline & $\mathbf{N}(\%)$ & $\mathbf{O R}$ & $\mathbf{9 5 \%} \mathbf{C l}$ & $\boldsymbol{\chi} \mathbf{2}$ & $\mathbf{P}$ \\
\hline Females & $24(22.2)$ & 2.4 & $0.5-10.6$ & 1.3 & 0.244 \\
\hline North-Center & $20(23.8)$ & 2.0 & $0.7-6.0$ & 1.7 & 0.194 \\
\hline Age 18-24 & $2(10.0)$ & 1.01 & $0.95-1.1$ & 0.1 & 0.6 \\
\hline Age 25-64 & $19(17.4)$ & 0.5 & $0.9-1.3$ & 1.1 & 0.291 \\
\hline Age > 64 & $6(33.3)$ & 2.3 & $0.6-8.8$ & 1.5 & 0.214 \\
\hline *MDQ > 7 & $\mathbf{7 . 5 ( 4 1 . 7 )}$ & $\mathbf{3 . 6}$ & $\mathbf{1 . 1 - 4 0 . 5}$ & $\mathbf{4 . 8}$ & $\mathbf{0 . 0 2 8}$ \\
\hline${ }^{*}$ Comorbidity PD & $\mathbf{9 . 6 ( 5 3 . 3 )}$ & $\mathbf{1 7 . 2}$ & $\mathbf{6 - 4 9 . 2}$ & $\mathbf{2 7 . 2}$ & $\mathbf{0 . 0 0 0 1}$ \\
\hline${ }^{*}$ Comorbidity DOC & $2.8(40.0)$ & 2.9 & $0.5-1.3$ & 0.8 & 0.369 \\
\hline${ }^{*}$ Comorbidity GAD & $\mathbf{6 . 9 ( 4 3 . 1 )}$ & $\mathbf{4 . 2}$ & $\mathbf{1 . 2 - 1 3 . 8}$ & $\mathbf{5 . 6}$ & $\mathbf{0 . 0 1 8}$
\end{tabular}

*Standardized by age, sex and residence (N/S); ${ }^{\circ}$ s overall sample receiving ADs (with exclusion of DE point prevalence) ${ }^{\circ}$ The Odds Ratio is calculated vs all other age frequencies
Depressive episodes are the most prevalent component in bipolar disorders, even when, as in a community, they are showing a clinical picture not meeting criteria for $\mathrm{DE}$. There is a growing awareness that treatment of bipolar depression is one of the greatest challenges in modern psychiatry $[19,20]$ since response to antidepressants is often unsatisfactory despite the overuse of these agents [19]. Other studies also suggest that treating bipolar depression with antidepressants is likely a bad practice $[20,21]$. There is indeed a strong rationale for a cautious approach to antidepressant use in bipolar disorder [18,22], which is based on the following findings:

(i) The risk of antidepressant-induced mood-cycling is high [23].

(ii) Antidepressants have not been shown to definitively prevent suicides and reduce

mortality, unlike long-term lithium treatment [24].

(i) Antidepressants have been shown less effective than mood stabilizers or atypical antipsychotics in acute bipolar depression and less effective than mood stabilizers in preventing depressive relapse in $\mathrm{BD}$. A recent systematic review and meta-analysis, reexamining the efficacy and safety of antidepressants use for acute treatment of bipolar depression, found antidepressants not statistically superior to placebo or other current standard treatment for bipolar depression [25].

European guidelines exert a more flexible attitude towards the use of antidepressants, whereas currently published American guidelines explicitly do not recommend antidepressants in the treatment of bipolar depression, unless the depressive episode is severe [26]. Our study indicates that antidepressants are broadly used (20\% of people) in a large community subsample with SD and is strictly associated with bipolar disorders with the possible induction of mood-cycling in the subsample. 
Table 5 Well being (SF-12) by treatment: SD, Sub-threshold Depression (HRDS > 10 without criteria for lifetime Depressive Episode); DE, Depressive Episode point prevalence; Total Depressive Symptoms = SD plus DE

\begin{tabular}{|c|c|c|c|c|c|c|}
\hline & First line $A D$ & Second line AD & Only BDZ & No $A D$ or $B D Z$ & $\mathrm{~F}$ & $P$ \\
\hline${ }^{\circ} \mathrm{SD}$ & $\begin{array}{l}30.8+/-4.5 \\
(n=20)\end{array}$ & $\begin{array}{l}30.4+/-4.3 \\
(n=7)\end{array}$ & $\begin{array}{l}28.3+/-4.3 \\
(n=35)\end{array}$ & $\begin{array}{l}29.1+/-5.1 \\
(n=75)\end{array}$ & $\begin{array}{l}\text { (DF 3,133, 136) } \\
1.3\end{array}$ & 0.288 \\
\hline${ }^{*} \mathrm{DE}$ & $31.6+/-5.6^{*}(n=17)$ & $30.3+/-4.9(n=14)$ & $28.6+/-5.1(n=9)$ & $25.8+/-5.1^{*}(n=15)$ & $\begin{array}{l}\text { (DF 3,51,54) } \\
1.8\end{array}$ & 0.002 \\
\hline §Total depressive symptoms & $\begin{array}{l}31.2+/-5.0 \\
(n=37)\end{array}$ & $\begin{array}{l}30.3+/-4.7 \\
(\mathrm{n}=21)\end{array}$ & $\begin{array}{l}28.4+/-4.5 \\
(n=44)\end{array}$ & $\begin{array}{l}28.5+/-5.1 \\
(n=90)\end{array}$ & $\begin{array}{l}\text { (DF 3, 188,191) } \\
3.0\end{array}$ & 0.0019 \\
\hline
\end{tabular}

T test Bonferroni 1vs4, 51 DF zP $<0.05$, Not Significant differences in the other comparisons; ${ }^{\circ} t$ test Bonferroni 133 DF, No significant differences; $\S \mathrm{t}$ test Bonferroni $188 \mathrm{DF}$, No significant differences

Question arises as to whether or not subjects with SD treated with antidepressants need to be further treated. This issue requires some examination of our results in light of results reported in recent literature. First, according to the hypothesis proposed by Ghaemi [1], our study indicate that the antidepressant use does not appear to be associated with improvement in the quality of life of people with SD; this is in contrast to people with DE in whom the use of first-line of antidepressants appears to be associated with a better quality of life. This finding needs to be confirmed by further studies, nonetheless, the results are in agreement with the findings of a recent review of clinical randomized trials, which suggest that there is no clinically significant difference between antidepressants and placebo in patients with minor depression [27].

Second, subject with SD and positivity for MDQ include: a) people with manic episode, fulfilling the criteria for Bipolar Disorders; people with hypomanic episode (not meeting the criteria for manic episode) including, b) people with cyclothymic disorder (the essential features of cyclothymic disorder is a chronic, fluctuating mood disturbance involving numerous periods of hypomanic and depressive symptoms), and/or c) people with hypomanic episode who do not meet the criteria for cyclothymic disorder (they should be classified as Bipolar Disorder Not Otherwise Specified).

As with Bipolar Disorder, use of antidepressants in cyclothymic disorder is typically not recommended, unless they're combined with a mood stabilizer. As with bipolar disorder, taking antidepressants alone can trigger potentially dangerous manic episodes. Patients with cyclothymia may switch to type II illness when treated with antidepressants [28]. Some evidence indicates that cyclothymia may be also associated with high risk for switch to rapid cyclicity [29]. Concerning the risk about switch to mania in people with SD and singular/isolated episode of hypomania using antidepressants, some studies suggest a similar risk in Bipolar Disorder Not Otherwise Specified than in other Bipolar Disordes [30]. Thus, people with SD and mania/hypomania detected by MDQ positivity are in a group where the use of antidepressants alone is counterindicated. In our study, this sub-sample is represented by $7.3 \%$ of the total SD in the community.

Third, a strong association between MDQ positivity, SD and anxiety disorders as Panic Disorder and Generalized Anxiety Disorders was found in our study. In these Anxiety disorders, antidepressants are an efficacious treatment and SSRI, as previous cited, are indicated as the first choice for treatment as per most treatment guidelines for anxiety disorders [15-17,31]. Nevertheless it was be found that co-morbidity with anxiety spectrum disorders and anxiety disorders is associated with rapid switching [32], thus the use of $\mathrm{AD}$ alone (without mood stabilizers) in people with SD, MDQ positivity and anxiety disorders may be an option to be considered with extreme caution. Therefore, the use of antidepressants in SD and Anxiety disorders must be preceded by an efficacious screening for mania/ hypomania.

Fourth, a large number of studies have found that counseling and psychosocial therapies in sub threshold depression is highly effective, at least in the short-term [33]. Similarly a brief psychological therapies were effective for anxiety [33]. Thus, antidepressants do not appear to have significant advantages for treating SD, and, it may even be dangerous if used in people with SD and MDQ positivity. Our results, together with the results of the recent above cited systematic review [27], suggest that antidepressants should not be considered for treatment of individuals with SD.

\section{Limitations of the study}

Our study has some significant limitations: first, some of the phenomena observed have a very low prevalence despite the use of a large sample of around 4,000, thus the results need to be considered with caution and confirmed by additional surveys. Second, the observational design is ineffective to account for people's well being related to a treatment; in this perspective a community survey have to be considered only as a source of hypothesis and these specific results must be considered only as an heuristic contribute. Third, the sample is 
representative of certain areas in Italy and is not representative of the nation as a whole.

Finally, serious doubts have been raised on the ability of the MDQ to detect milder bipolar disorders [34]. As a matter of fact, according to Zimmerman et al [35] MDQ shows low sensitivity in clinical settings among cases affected by bipolar disorder. The cross-national validation studies of MDQ reported good accuracy in the UK [36], Turkey [37] and Spain [38] and less encouraging results in France [39]. The validation of the Italian version of MDQ in the general population [3] revealed fairly good accuracy, with sensitivity of 0.70 , specificity of 0.87 , PPV of 0.47 and NPV of 0.95 (using a cut-off of seven, as in the present study). Moreover, the comparison of the MDQ with another screening instrument for Bipolar disorder (Hypomania Checklist (HCL32)] showed high consistency [40]

\section{Conclusions}

Our study appears to suggest a greater caution in prescribing antidepressants to people with SD, especially antidepressants with higher risk to induce mania, particularly to people with concomitant anxiety disorders. In $\mathrm{SD}$, a well-designed assessment to evaluate the presence of previous manic or hypomanic symptoms should be mandatory before prescribing antidepressants.

\section{Acknowledgements}

This study was supported by a grant of AIFA (Agenzia Italiana del Farmaco) Number FARM54S73S, approved in 2005.

\begin{abstract}
Author details
${ }^{1}$ Department of Public Health, University of Cagliari, Cagliari, Italy 2Department of Psychiatry, Harvard Medical School, Boston, Massachusetts, USA. Inter-University Center for Behavioural Neurosciences, DPMSC, University of Udine, Udine, Italy. ${ }^{4}$ Department of Drug Sciences, University of Catania, Italy. ${ }^{5}$ Department of Psychiatry, Neurobiology, Pharmacology and Biotechnology, University of Pisa, Pisa, Italy. ${ }^{6}$ Department of Neurological and Psychiatric Sciences, University of Bari, Bari, Italy. ${ }^{7}$ Department of Neurology and Psychiatry, Florence University, Firenze, Italy. ${ }^{8}$ Department of Psychiatry, Reald University, Vlore, Albania. ${ }^{9}$ Department of Neuroscience and Cell Biology, University of Texas Medical Branch, Galveston, Texas, USA.

${ }^{10}$ Department of Science of Health, University of L'Aquila, L'Aquila, Italy.
\end{abstract}

\section{Authors' contributions}

MGC participated in the design and coordination of the study, in the acquisition and analysis of the data and drafted the manuscript. LT participated in the analysis of the data and drafted the manuscript. MB, FC, LdO, GdS, CF participated in the design of the study, in the acquisition and analysis of the data and drafted the manuscript. MCH participated in the design and coordination of the study. MFM and MEL participated in acquisition of data and critical revision of the manuscript. KMB participated in the analysis of the data and drafted the manuscript. MC and FD participated in the design of the study, in the acquisition and analysis of the data and drafted the manuscript. All authors read and approved the final manuscript.

\section{Competing interests}

The authors declare that they have no competing interests.
References

1. Ghaemi SN: Why antidepressants are not antidepressants: STEP-BD, $\operatorname{STAR}^{*} \mathrm{D}$, and the return of neurotic depression. Bipolar Disord 2008, 10(8):957-68.

2. Benazzi F: Various forms of depression. Dialogues Clin Neurosci 2006, 8(2):151-61.

3. Carta MG, Aguglia E, Bocchetta A, Balestrieri M, Caraci F, Casacchia M, Dell'Osso L, Sciascio GD, Drago F, Faravelli C, Lecca ME, Moro MF, Morosini PL, Nardini M, Palumbo G, Hardoy MC: The Use of Antidepressant Drugs and the Lifetime Prevalence of Major Depressive Disorders in Italy. Clin Pract Epidemiol Ment Health 2010, 6:94-100.

4. Carta MG, Hardoy MC, Cadeddu M, et al: Psychotropic drug use in a sample of general population in the Sardinia region. Epidemiol Psichiatr Soc 2003, 12(4):287-92

5. First M, Spitzer R, Gibbon M, Williams J: Structured clinical interview for DSM-IV axis I disorders, research version, non-patient edition (SCID-I/NP). New York: Biometrics Research, New York State Psychiatric Institute; 1997.

6. Carta MG, Lecca ME, Hardoy MC: "The use of drugs for mood disorders in Italy, Progetto AIFA: FARM54S73S. Validità comparativa dell'intervista A. N.T.A.S Advanced Neuropsychiatric Tools and Assessment Schedule". Convegno ricerca indipendente sul farmaco. Roma: AIFA; 2008.

7. Hirschfeld RM, Calabrese JR, Weissman MM, et al: Screening for bipolar disorder in the community. J Clin Psychiatry 2003, 64(1):53-9.

8. Hardoy MC, Cadeddu M, Murru A, Dell'Osso B, Carpiniello B, Morosini PL, Calabrese JR, Carta MG: Validation of the Italian version of the "Mood Disorder Questionnaire" for the screening of bipolar disorders. Clin Pract Epidemol Ment Health 2005, 1:8.

9. Hamilton M: Development of a rating scale for primary depressive illness. Br J Soc Clin Psychol 1967, 6:278-96.

10. Ware J Jr, Kosinski M, Keller SD: A 12-Item Short-Form Health Survey: construction of scales and preliminary tests of reliability and validity. Med Care 1996, 34(3):220-33.

11. Judd LL, Paulus MP, Wells KB, Rapaport MH: Socioeconomic burden of subsyndromal depressive symptoms and major depression in a sample of the general population. Am J Psychiatry 1996, 153(11):1411-7.

12. Angst J, Merikangas KR, Preisig M: Subthreshold syndromes of depression and anxiety in the community. J Clin Psychiatry 1997, 58(Suppl 8):6-10.

13. Carta MG, Angst J: Epidemiological and clinical aspects of bipolar disorders: controversies or a common need to redefine the aims and methodological aspects of surveys. Clin Pract Epidemol Ment Health 2005, 1(1):4.

14. Carta MG, Aguglia E, Balestrieri M, Calabrese JR, Caraci F, Dell'Osso L, Di Sciascio G, Drago F, Faravelli C, Lecca ME, Moro MF, Nardini M, Palumbo G, Hardoy MC: The Lifetime Prevalence of Bipolar Disorders and the use of Antidepressant Drugs in Bipolar Depression in Italy. J Affect Disord.

15. American Psychiatric Association: Practice Guideline for the Treatment of Patients With Panic Disorder. Am J Psychiatry 1998, 155(May suppl).

16. Ballenger JC, Davidson JRT, Lecrubier Y, Nutt DJ, Baldwin DS, den Boer JA, Kasper S, Shear MK: Consensus statement on panic disorder from the International Consensus Group on Depression and Anxiety. J Clin Psychiatry 1998, 59(Suppl 8):47-54.

17. Pinder RM: Treatment of generalized anxiety disorder. Neuropsychiatr Dis Treat 2007, 3(2):183-184.

18. Rakofsky JJ, Dunlop BW: Treating nonspecific anxiety and anxiety disorders in patients with bipolar disorder: a review. J Clin Psychiatry 2011, 72(1):81-90.

19. Baldessarini RJ, Vieta E, Calabrese JR, Tohen M, Bowden CL: Bipolar depression: overview and commentary. Harv Rev Psychiatry 2010, 18(3):143-157.

20. Ghaemi SN, Hsu DJ, Soldani F, Goodwin FK: Antidepressants in bipolar disorder: the case for caution. Bipolar Disord 2003, 5(6):421-433.

21. Vieta E: Role of antidepressants in bipolar depression. $J$ Clin Psychiatry 2010, 71(9):e21..

22. Ostacher MJ: The evidence for antidepressant use in bipolar depression. J Clin Psychiatry 2006, 67(Suppl 11):18-21.

23. Salvi V, Fagiolini A, Swartz HA, Maina G, Frank E: The use of antidepressants in bipolar disorder. J Clin Psychiatry 2008, 69(8):1307-1318.

24. Müller-Oerlinghausen $B$, Lewitzka U: Lithium reduces pathological aggression and suicidality: a mini-review. Neuropsychobiology 2010, 62(1):43-49. 
25. Sidor MM, Macqueen GM: Antidepressants for the acute treatment of bipolar depression: a systematic review and meta-analysis. J Clin Psychiatry 2011, 72(2):156-67.

26. Hausmann A, Hörtnagl C, Walpoth M, Fuchs M, Conca A: Are there substantial reasons for contraindicating antidepressants in bipolar disorder? Part II: facts or artefacts? Neuropsychiatr 2007, 21(2):131-158.

27. Barbui C, Cipriani A, Patel V, Ayuso-Mateos JL, van Ommeren M: Efficacy of antidepressants and benzodiazepines in minor depression: systematic review and meta-analysis. Br J Psychiatry 2011, 198(1):11-6.

28. Akiskal HS, Djenderedjian AT, Rosenthal RH, Khani MK: Cyclothymic disorder: validating criteria for inclusion in the bipolar affective group. Am J Psychiatry 1997, 134(11):1227-33.

29. Kilzieh N, Akiskal HS: Rapid-cycling bipolar disorder. An overview of research and clinical experience. Psychiatr Clin North Am 1999, 22(3):585-607.

30. Ghaemi SN, Boiman EE, Goodwin FK: Diagnosing bipolar disorder and the effect of antidepressants: a naturalistic study. J Clin Psychiatry 2000, 61(10):804-8.

31. Baldwin DS, Anderson IM, Nutt DJ, Bandelow B, Bond A, Davidson JR, den Boer JA, Fineberg NA, Knapp M, Scott J, Wittchen HU, British Association for Psychopharmacology: Evidence-based guidelines for the pharmacological treatment of anxiety disorders: recommendations from the British Association for Psychopharmacology. J Psychopharmacol 2005, 19(6):567-96.

32. MacKinnon DF, Zandi PP, Gershon E, Nurnberger JI Jr, Reich T, DePaulo JR: Rapid switching of mood in families with multiple cases of bipolar disorder. Arch Gen Psychiatry 2003, 60(9):921-8.

33. Cape J, Whittington C, Buszewicz M, Wallace P, Underwood L: Brief psychological therapies for anxiety and depression in primary care: meta-analysis and meta-regression. BMC Med 2010, 8:38

34. Merikangas KR, Akiskal HS, Angst J, Greenberg PE, Hirschfeld RM, Petukhova M, Kessler RC: Lifetime and 12-month prevalence of bipolar spectrum disorder in the National Comorbidity Survey replication. Arch Gen Psychiatry 2007, 64(5):543-52.

35. Zimmerman M, Galione JN, Ruggero CJ, Chelminski I, McGlinchey JB, Dalrymple K, Young D: Performance of the mood disorders questionnaire in a psychiatric outpatient setting. Bipolar Disord 2009, 11(7):759-65.

36. Twiss J, Jones S, Anderson I: Validation of the Mood Disorder Questionnaire for screening for bipolar disorder in a UK sample. J Affect Disord 2008, 110(1-2):180-4

37. Konuk N, Kiran S, Tamam L, Karaahmet E, Aydin H, Atik L: Validation of the Turkish version of the mood disorder questionnaire for screening bipolar disorders. Turk Psikiyatri Derg 2007, 18(2):147-54.

38. Sanchez-Moreno J, Villagran JM, Gutierrez JR, Camacho M, Ocio S, Palao D, Querejeta I, Gascon J, Sanchez G, Vieta E, EDHIPO (Hypomania Detection Study) Group: Adaptation and validation of the Spanish version of the Mood Disorder Questionnaire for the detection of bipolar disorder. Bipolar Disord 2008, 10(3):400-12.

39. Weber Rouget B, Gervasoni N, Dubuis V, Gex-Fabry M, Bondolfi G, Aubry JM: Screening for bipolar disorders using a French version of the Mood Disorder Questionnaire (MDQ). J Affect Disord 2005, 88(1):103-108.

40. Carta MG, Hardoy MC, Cadeddu M, Murru A, Campus A, Morosini PL, Gamma A, Angst J: The accuracy of the Italian version of the Hypomania Checklist (HCL-32) for the screening of bipolar disorders and comparison with the Mood Disorder Questionnaire (MDQ) in a clinical sample. Clin Pract Epidemol Ment Health 2006, 2:2.

\section{Pre-publication history}

The pre-publication history for this paper can be accessed here: http://www.biomedcentral.com/1471-244X/11/164/prepub

doi:10.1186/1471-244X-11-164

Cite this article as: Carta et al: Sub-threshold depression and antidepressants use in a community sample: searching anxiety and finding bipolar disorder. BMC Psychiatry 2011 11:164.

\section{Submit your next manuscript to BioMed Central and take full advantage of:}

- Convenient online submission

- Thorough peer review

- No space constraints or color figure charges

- Immediate publication on acceptance

- Inclusion in PubMed, CAS, Scopus and Google Scholar

- Research which is freely available for redistribution

Submit your manuscript at www.biomedcentral.com/submit 